\section{Studies on Pancreatitis}

SIR,-I read with much interest the instructive article "Studies in Pancreatitis" (Journal, December 19, 1953, p. 1335), and the authors are to be congratulated on endeavouring to throw some light on the vexed problems concerning the surgery of the pancreas.

However, few would agree that in cases of acute pancreatitis " if an occasional laparotomy is needlessly performed little harm to the patient is likely to follow." The consensus of opinion is that operative interference in acute pancreatitis carries a mortality of $30 \%$, as compared with $3 \%$ treated symptomatically, and who are mostly fulminating cases who are doomed whatever may be done. Therefore every precaution must be taken to avoid laparotomy, even in the occasional case, and a valuable physical sign in acute pancreatitis is tenderness over the left renal angle-i.e., over the tail of the pancreas.

I have for many years been interested in the difficult problem of the "post-cholecystectomy syndrome," to which I have referred in a recent article. ${ }^{1}$ My experience agrees with those expressed by the authors, with one exception. I believe that spasm, or even fibrosis of the sphincter of Oddi, is a definite clinical entity, manifested by recurrent attacks of dyspepsia, colicky pains, and even slight jaundice. These attacks are usually relieved by pethidine, but, if they incapacitate the patient, division of the sphincter, preferably by means of a sphincterotome, not only relieves back pressure on the liver but also provides drainage of the main pancreatic duct, and thus lessens the risk of progressive infection. I have performed this operation on 14 patients, in 10 of whom symptoms were entirely relieved, and. the remaining 4 were improved sufficiently enough to be grateful. -.I am, etc.,

London, W.1. McNeILl Love.

REFBRENCE

1 Brit. J. Surg., 1952, 40, 214.

Appendicitis in the Course of Measles

Sir,--The article by Dr. W. H. Galloway on this subject (Journal, December 26,1953, p. 1412) is of interest to all who have to deal with children, and especially those who have the difficult task of deciding whether the appendix of a young child is inflamed or no. There seem to be three points of importance.

(1) It might be better to separate off a group and call it pseudo-appendicitis. In Dr. Galloway's seven cases all the appendices were removed, but two were "apparently normal," one showed "slight redness," and one was "slightly inflamed." Lacking further details one can only suggest that these four were possibly removed unnecessarily. (2) In making a diagnosis, a count of the white blood cells may be useful. Dr. Galloway does not give his figures, but it is usual to find a leucopenia in early measles. I have notes of two cases which were seen last spring. They had both been admitted to hospital with the diagnosis of acute appendicitis. One, a boy of 7 , had his appendix removed, and it was found to be covered with Koplik's spots but otherwise normal. A white blood count taken next day showed 7.500 cells per c.mm., of which $81 \%$ were polymorphs. The measles rash appeared two days later. In the other child, a girl of 4 , the white blood count was 4,300 , with $80 \%$ polymorphs. Operation was not performed; the rash appeared next day and she made a perfect recovery. (3) The routine use of sulphonamides in measles is important in preventing respiratory complications, especially in children under 3 years of age.

Obviously there are some cases where it would be dangerous to delay and exploratory laparotomy is essential ; but as often as not the situation is not so grave and a period of observation in hospital with special attention to the search for Koplik's spots in the mouth and a white blood count may solve the problem without surgical and anaesthetic intervention.-I am, etc.,

H. R. E. Wallis.
The College of General Practitioners

SIR,-I really cannot allow to pass unchallenged Dr. J. Inglis Cameron's remarks in the Journal of December 19, 1953 (p. 1376), on the future of the College of General Practitioners. While it is not my purpose to argue with his suggestion that there should be no delay in applying for a royal charter, although it would seem to me that such an honour should be conferred upon a body which has proved its worth, I am wholly against advocating a registrable diploma of general practice.

Dr. Cameron's concern for improving the standard of general practice is, of course, understandable, but 1 am sure that his traditional plan for attaining this end is the wrong one. The mind boggles at the thought of yet another diploma to be added to the surfeit of examinations for this and that which we have already. And the fact that it will shortly be impossible to practise medicine at all after the completion of one's house appointments without a "higher qualification " makes a mockery of the qualifying examination. If it be true, as Dr. Cameron asserts, that the equality of colleges partly depends upon whether they are also examining bodies, then I am sure that, when it becomes widely appreciated that to-day one's diploma count is more important than one's experience, the problem will cease to exist among the ensuing inevitable and widespread changes. (If the loss of a lively source of income is felt too deeply, then I for one will be glad to subscribe to an annual flag day.)

No, let us resist the temptation to foster this present impossible system of promotion by creating an examination for general practitioners, and instead allow the College of General Practitioners to prove its worth by influencing the revolution in medical education which is now spluttering into life. Let it ensure that the curriculum for the qualifying examination is designed to produce general practitioners, and not housemen. Let it then encourage a system of promotion based on experience instead of academic honours. In this way, perhaps the new College will be able to find its own feet by helping to recover the dignity of the established royal colleges, which is waning in face of this craze for collecting diplomas instead of beer-bottle tops. Until then, we are in no position to ridicule the reasoning of the patient who prefers his general practitioner to be an M.R.C.S., L.R.C.P., rather than a plain M.B., B.S. - "After all, has he not eight letters as against four? He must be twice as good!"-I am, etc.,

Barnstaple.

G. V. BALMFORTH.

\section{Ferrous Sulphate Poisoning}

SiR,-Dr. F. G. M. Ross's article (Journal, November 28 , 1953 , p. 1200) prompts us to record a similar case of pyloric obstruction following ferrous sulphate poisoning. At the same time we wish to support the views expressed in the leading article in the same issue on "Accidental Poisoning of Children" (p. 1207). These show there are many medicines prescribed for adults which should be labelled "Poisonous for Children," and in this particular instance the manufacturers of the green sugar-coated ferrous sulphate pills should also be urged to make their preparation less like "smarties," the sugar-coated chocolate sweets beloved by all small children. Attempts along these lines made by the Paediatric Department in Oxford have been unsuccessful, and it is to be huped that another appeal with the weight of the B.M.A. behind it may be more effective. Ferrous sulphate is extensively prescribed for mothers attending antenatal and post-natal clinics, and after the arrival of the new babe it has seemed to us that it is the toddler of 1-2 years, temporarily less well supervised, who is in danger; certainly the majority of the seven cases seen here in the last three years fall into this category.

A baby girl, aged 16 months, arrived in hospital from the country just over an hour after swallowing an unknown number of ferrous sulphate tablets, 20 of which she had vomited immediately. She was pale and restless on admission, and vomiting 
blood-stained fluid; a stomach washout with sodium bicarbonate produced more fresh and altered blood, but no tablets. She continued to vomit, and at the end of 24 hours looked ill and shocked. Her haemoglobin had fallen to $55 \%$, so she was given a small blood transfusion, followed by one of glucose saline to maintain hydration. Her condition then steadily improved and she was discharged well after 12 days, taking a light diet without vomiting, and weighing $18 \mathrm{lb} .10 \mathrm{oz}$. (8.38 kg.). Seen after three weeks, her appetite was said to have been poor, she had vomited occasionally, but had gained weight. Seen again four weeks later, however, she presented with symptoms of pyloric obstruction, weighing only $15 \mathrm{lb} .11 \mathrm{oz}$. (7.06 kg.).

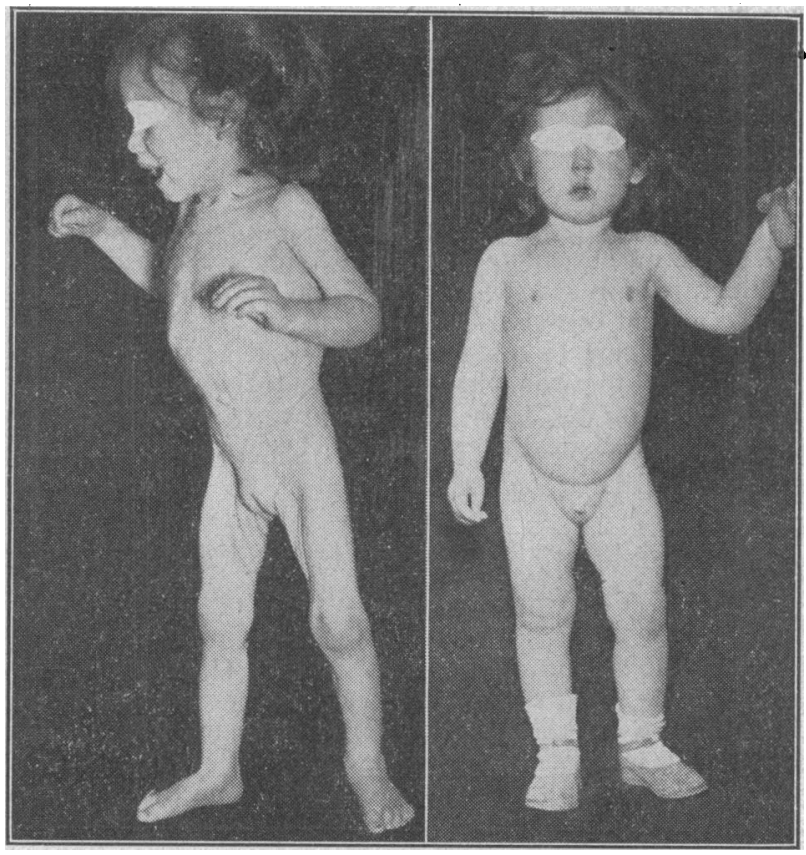

Before operation.

$3 \frac{1}{2}$ months after operation.

At operation many adhesions were found between the stomach and surrounding viscera, and in particular those between stomach and liver were so tough as to necessitate sharp dissection for their separation. The distal half of the stomach was thickened, rigid and fibrotic, the proximal half was hypertrophied and dilated, but was otherwise normal, as was the duodenum. The fibrotic portion of stomach was resected, a Billroth I type of partial gastrectomy being performed. The post-operative course was satisfactory, and a rapid gain of $4 \mathrm{lb}$. $(1.8 \mathrm{~kg}$.) in the first four weeks occurred. Subsequent progress during the past two years has continued to be good.

The pathologist's report on the portion of stomach removed stated : "The gastric wall almost up to the upper limit of resection was grossly fibrotic and $0.75 \mathrm{~cm}$. in thickness. The mucosal surface had a granular brownish appearance, and the lumen of the whole pyloric antrum and pylorus was narrowed to about $0.1 \mathrm{~cm}$. diameter. Histology: Over part of the specimen gastric mucosa remains, while elsewhere this is replaced by a granulation tissue layer in areas of ulceration, or by squamous epithelium which is presumably due to metaplasia. The mucosa shows slight irregularity of pattern, with scattered small cysts lined by flattened epithelium, and exaggerated mucus secretion. The squamous epithelium is regular with no invasive tendency. The submucosa and granulation tissue are congested and oedematous, with a very dense inflammatory exudate including polymorphonuclear leucocytes, plasma cells, and lymphocytes. The muscularis and subserosa are also congested, with interstitial haemorrhage, but here the most obvious change is a diffuse fibroblastic proliferation. Inflammatory infiltration similar to that in the submucosa extends down into these layers, chiefly around vessels, and iron-containing histiocytes are present in large aggregates. The mucosal cells give only a weak staining reaction for iron, and the histiocytic accumulations may bo due to interstitial haemorrhage, but their extreme frequency makes this unlikely. A thin fibrinous layer covers the serosa. The appearances as a whole are in kceping with a corrosive poison, and the intra-epithelial iron is a strong indication that the poison was or included an iron compound."
It is evident that "pyloric obstruction" does not adequately describe the pathological lesion, which is in fact an extensive fibrosis affecting all coats of the distal half of the stomach and leading to a near obliteration of its lumen.

In these cases of poisoning it appears that the children swallow the tablets whole, and it is only after the sugar coating dissolves that the caustic action of the ferrous sulphate occurs. The oesophagus, therefore, escapes completely, and it follows that the maximum damage is done to the pyloric end of the stomach. This is borne out in Ross's case, where the $x$-ray several days before operation showed obstruction to barium in the distal half of the stomach. The appropriate treatment must be, therefore, to relieve the gastric obstruction by a gastro-enterostomy or gastrectomy.-We are, etc.,

Orford.

\section{A. Elliot-Smith.} Pamela A. Davies.

\section{Tales of a Pomander}

SIR,-Professor Charles Singer (Journal, December 19 , 1953, p. 1373) is surely wrong in stating that Richard Mead made no important contribution to medical science. In 1748 Mead first described the occurrence of fatty liver in a case of diabetes mellitus, and held the view that the liver was in some way concerned in the aetiology of the disease. This was quite revolutionary in an age when medical opinion was divided between those who believed diabetes mellitus to be due to a "disordered assimilation" by the intestines and those who supported the theory of a "morbid affliction" of the kidneys, and, of course, antedated Claude Bernard's important discoveries by a hundred years. The wonder is that any man with Mead's reputation as a practising physician could have found the time to indulge in medical research.-I am, etc.,

London, S.E.1.

\section{A. Paton.}

\section{Medical Needs in the Gold Coast}

SrR,-Dr. D. B. Scott's letter (Journal, December 19, 1953, p. 1377) is very interesting. First, let me say that $I$ was in the Gold Coast Medical Service until June, 1953-not years ago. Next, it is certain that the Government would eagerly offer permanent pensionable posts to specialists if they could be found. The response to advertisements has been uniformly poor, so, rightly or wrongly, they seem to think that if they offered contract terms a few highly qualified men could be found by a form of secondment. For instance, a consultant could go to the Gold Coast to do, say, two tours with full assurance that only strictly temporary locums would assist his group in his absence. After his contract he would then be able to return to his former job invigorated, having also given new vitality to the Colony. This scheme is clearly capable of development and diversification. In the interest of avoiding waste of professional men, could the B.M.A. not usefully press for S.H.M.O. posts for ex-colonial specialists and for similar measures?

Finally, a vague air of dissatisfaction surrounds Dr. Scott's letter, and the reason for it is not quite clear. There are at least two fellow Cambridge men in the Gold Coast Medical Service, recently employed, who show every sign of enjoying their work.-I am, etc.,

Manchester.

K. A. TAYlor.

\section{Distinguishing a Psychopath}

SIR,-The exchange of views between eminent legal and psychiatric experts on the definition of a psychopath (Journal, November 28,1953 , p. 1224) serves to show how difficult it is for lawyers and alienists to attain mutual understanding. The crux of the problem appears to lie in the fact that lawyers, accustomed to deal:ng in tangibles, are for ever pressing the psychiatrist to confine himself to nice definitions. Although the diagnostic term "psychopathic personality" is widely recognized among psychiatrists, nobody has succeeded in defining it in a universally acceptable or succinct manner. The definition given by Dr. Denis Hill to the Royal Commission on Capital Punishment stresses 